\title{
CAPACITIVE LOAD BASED ON IGBTS FOR ON-SITE CHARACTERISATION OF PV ARRAYS
}

\author{
J. Muñoz ${ }^{(*)}$ and E. Lorenzo \\ Universidad Politécnica de Madrid. Instituto de Energía Solar. (UPM-IES). \\ Ciudad Universitaria s/n. 28040 Madrid. \\ ${ }^{(*)}$ E-mail: javier@ies-def.upm.es. Tel: +34 9154410 60. Fax: +34 915446341
}

\begin{abstract}
This paper describes the practical design of a portable capacitive load based on Insulated Gate Bipolar Transistors (IGBTs), which allows to measure the I-V characteristic of PV arrays with short-circuit currents up to $80 \mathrm{~A}$ and open circuit voltages up to $800 \mathrm{~V}$. Such measurements permit to characterize the on-site electrical performance of PV arrays under real operating conditions and also provide invaluable information for the detection of potential array anomalies, such as broken cells or defective connections. The presented I-V load is easy to reproduce and low-cost, which is within the reach of small-scale organisations involved in PV electrification projects.
\end{abstract}

Keywords: PV array, I-V characteristic, capacitive load 


\section{INTRODUCTION}

On-site measurement of the I-V characteristic of PV arrays is of interest by innumerable reasons. For example, as quality assurance tool, it allows determining the maximum array power under real operating conditions, which can be extrapolated to STC (Standard Test Conditions: $1000 \mathrm{~W} / \mathrm{m}^{2}$ normal irradiance, $25{ }^{\circ} \mathrm{C}$ cell temperature and AM 1.5 solar spectrum) and compared with installed rated power or contractual specifications agreed between vendors and customers. Besides, as diagnosis or maintenance tool, the shape of the I-V characteristic provides invaluable information on the detection of possible PV array anomalies, such as disconnected sub-arrays, broken cells, shading, mismatch, and so on.

The capacitive load is the most common method used by commercial equipment for measuring the I-V curve of PV devices (Neuenstein, Albers, 2004), and its use is recommended by international guidelines and standards for measuring PV arrays from 2 up to $50 \mathrm{kWp}$ (Blaesser, Munro, 1995; IEC, 1995). Based on this method, the UPM-IES developed a former equipment in 1994, which was used for the first time in the quality control of PV arrays performed at 1 MW Toledo-PV plant (Lorenzo, Zilles, 1994). Although such equipment is still operating, it has certain disadvantages (e.g., its uncomfortable portability) and does not include several functions that must be independently performed (e.g., array short-circuit). These reasons, and the fact that commercial loads are still rather expensive and leave to be desired (Neuenstein, Albers, 2004), lead us to develop again a self-made and improved capacitive load based on IGBTs, whose design is described in this paper with the aim of encouraging the use and development of similar equipment, not only by research laboratories or universities, but also by small-scale organisations (promoters, companies, utilities, etc.) involved in PV 
electrification projects. The new load can measure the I-V curve of PV arrays with short-circuit currents up to $80 \mathrm{~A}$ and open circuit voltages up to $800 \mathrm{~V}$. Until now, more than $20 \mathrm{PV}$ arrays (with currents up to $70 \mathrm{~A}$ and voltages up to $700 \mathrm{~V}$ ) have been satisfactorily tested as a part of acceptance procedures applied within several rural electrification projects carried out in the South of Morocco (Muñoz et al., 2003; Narvarte et al., 2004) .

After a summary review of the principles of operation of an ideal capacitive load, the electronic design of the prototype (power, drive and control circuits) and its cost are presented. A latter section outlines the testing procedure that we use for the outdoor characterization of PV arrays.

\section{PRINCIPLES OF OPERATION}

Figure 1-a shows the schematic of an ideal capacitive load, consisting of a switch and a capacitor, which operates this way. If the capacitor is discharged (zero voltage across its terminals) and the switch closes up, the PV array delivers its short-circuit current and the capacitor charge starts at that very instant. From that moment, the capacitor voltage increases moving the operating $\mathrm{I}-\mathrm{V}$ point from short-circuit $\left(\mathrm{I}=\mathrm{I}_{\mathrm{SC}}\right.$, $\mathrm{V}=0$ ) until it reaches the open circuit voltage $\left(\mathrm{I}=0, \mathrm{~V}=\mathrm{V}_{\mathrm{OC}}\right)$, at which the capacitor charge finishes. Figure 1-b shows the evolution of current and voltage waveforms during this charging process.

Figure 1. (a) Ideal capacitive load composed of a switch and a capacitor. (b) Current and voltage waveforms after closing the switch in $\mathrm{t}=0$. 
Assuming that the PV array has the ideal square I-V characteristic represented in figure 2, the capacitor charging time, $\mathrm{t}_{\mathrm{C}}$, depends on its capacitance, $\mathrm{C}$, and on the instantaneous values of $\mathrm{I}_{\mathrm{SC}}$ and $\mathrm{V}_{\mathrm{OC}}$, through the following equation:

$$
t_{C}=\frac{V_{O C}}{I_{S C}} C
$$

In real I-V characteristics, as the current decreases as the voltage increases (figure 2), the charging time is slightly higher than the calculated using the previous equation. Nevertheless, such approximation is more than enough for our present design purposes. As a rule of thumb, charging times are usually chosen in the range between 20 and 100 ms (Blaesser, Munro, 1995). These short times reduce the overheating and the size of components, such as IGBTs and capacitors, and permit to assume that the array operating conditions (irradiance and cell temperature) do not change during the I-V sweep. In the practise, it is not always possible matching the capacitance to the wide range of operating conditions and PV arrays characteristics. As result, charging times can reach several hundreds of milliseconds, which are still reasonable and should not be dangerous for the load.

Figure 2. Ideal (continuous line) and real (dotted line) I-V characteristics of a PV array.

\section{ELECTRONIC DESIGN}

\subsection{Power circuit}

Figure 3 shows the schematic of the real power circuit we have developed. Comparing it with the ideal capacitive load of figure 1-a, the switch can be identified as the IGBT2, and the capacitor as the parallel arrangement of capacitors C1 to C4. The 
functions of these and the remainder power circuit components, whose electrical characteristics are displayed in table 1, are the following:

- $\quad$ The IGBT2 connects the PV array with the capacitors C1 to C4.

- The capacitors C1 a C4 (4.7 mF / $450 \mathrm{~V}$ each one) are connected in parallel, which is equivalent to a capacitance equal to $18.8 \mathrm{mF}$. These capacitors can also be connected two in series and two in parallel (equivalent capacitance equal to $4.7 \mathrm{mF}$ ) for measuring, in principle, PV arrays with $\mathrm{V}_{\mathrm{OC}}$ in the range between 450 and $900 \mathrm{~V}$. However, the maximum $\mathrm{V}_{\mathrm{OC}}$ has been stated at $800 \mathrm{~V}$ in order to safeguard the electrical isolation of other circuit components.

- The resistor R3 equilibrates the voltage across the capacitors when they are connected in series, which prevents a voltage higher than $450 \mathrm{~V}$ across each one of them.

- The IGBT3 allows to discharge the capacitors through the resistor RD before performing a new I-V sweep. This discharging process takes several seconds and finishes when the capacitors voltage (indicated by a panel voltmeter) decreases below 5 V.

- The fuse F1 protects RD against the direct connection of the PV array, which can happen if the IGBT2 breaks down. IGBTs 2 and 3 are included in one package (half bridge power module).

- The sub-circuit composed of the push button P1, the fuse F2, the resistor RP, and the dry battery VB, allows to pre-charge the capacitors with a negative voltage before measuring the I-V curve. This negative voltage compensates the voltage drop across IGBTs, diodes, wiring, etc., ensuring that the array voltage starts in the second quadrant $(\mathrm{V}<0, \mathrm{I}>0)$ and crosses the short-circuit point $\left(\mathrm{V}=0, \mathrm{I}=\mathrm{I}_{\mathrm{SC}}\right)$. It is worth 
mentioning that three-quadrants inductive-capacitive loads have been proposed in the literature (Barbisio, 1996), which allow detecting some types of mismatching by the inspection of the $\mathrm{I}-\mathrm{V}$ characteristic in the fourth quadrant $(\mathrm{V}>0, \mathrm{I}<0)$.

- The fuse F2 protects the previous pre-charging sub-circuit against the possibility of pushing the button P1 without performing a previous discharge of the capacitors C1-C4. As commented above, it is necessary to ensure that the capacitor voltage be lower than $5 \mathrm{~V}$ before beginning the negative pre-charging process. The diode D3 prevents the discharge of the capacitors through RD and the parallel diode of the IGBT3 when the negative voltage is applied.

- The IGBT1 permits the isolated measurement of $\mathrm{I}_{\mathrm{SC}}$ (being strict, this measurement does not provide the exact value of $\mathrm{I}_{\mathrm{SC}}$ because the array voltage is higher than zero volts owing to the voltage drop across the IGBT1 and the diode D1, which ranges from 2 to $3 \mathrm{~V}$ ). The diode D1 protects the IGBT1 against the wrong polarity connection of the PV array. The IGBT1 belongs to one half bridge power module, whose other IGBT is unused and remains in reserve.

- The diode D2 prevents the discharge of capacitors C1-C4 across the IGBT1 when the latter short-circuits the PV array and the capacitors have not been previously discharged. It also protects the IGBT2 and the capacitors C1-C4 against the wrong polarity connection of the PV array.

- The resistor R1 and the potentiometer R2 divide the array voltage by 10, being the latter used as voltage sensor. The reduced voltage $\left(\mathrm{V}_{1}=0.1 \cdot \mathrm{V}\right)$ does not exceed the conventional isolation limit or measuring devices (typically, $600 \mathrm{~V}$ ). RS is a precision resistor, whose resistance is very small, which acts as current sensor by measuring the 
voltage drop across its terminals $\left(\mathrm{V}_{2}\right)$. Each sensor is externally accessible through two shrouded sockets, which must be connected to the data acquisition system.

Figure 3. Power circuit.

Table 1. Power circuit components.

Regarding the thermal design of the load, it is worth mentioning that the power circuit components are not sized for steady-state operation. For example, the instantaneous power dissipation in an IGBT at the maximum permitted current (80 A) is $320 \mathrm{~W}$ (considering the worst case of an IGBT whose collector-emitter saturation voltage is $4 \mathrm{~V}$ ). Despite of this, the heat sink has a sink-to-ambient thermal resistance equal to $1.4{ }^{\circ} \mathrm{C} / \mathrm{W}$ that would increase the sink temperature over the ambient in $450{ }^{\circ} \mathrm{C}$ (320 W $\left.\times 1.4{ }^{\circ} \mathrm{C} / \mathrm{W}\right)$, which is three times the maximum junction temperature of commercial IGBTs. Therefore, such power devices must rather rely on the short duration, or on the low magnitude, of the current surge. This is the case of IGBTs 2 and 3, which do not experience excessive internal temperatures because, for the former, the charging capacitor times are usually less than one second and, for the latter, the discharge capacitor current is less than 2 A. The IGBT1 requires greater attention because the duration of the short-circuit measurement depends on the equipment operator (as discussed below, the equipment is operated manually). Although the operator must ensure that the reading of short-circuit current does not exceed a safe limit of 5 seconds (more than enough to perform this measurement), the equipment incorporates a redundant protection that consists of a thermal switch placed in contact 
with the heat sink. If the temperature of the latter exceeds $60{ }^{\circ} \mathrm{C}$, the switch, which is normally closed, opens inhibiting the operator's control and turning-off the IGBT1.

In order to facilitate the transport (the whole weight is around $15 \mathrm{~kg}$ ), the equipment has been divided in two boxes. One (figure 4-a) contains IGBTs, resistors, diodes, etc., and also the drive and control circuits, which are described below. The other one (figure 4-b) contains the electrolytic capacitors and the pre-charging circuit. This way, the capacitors box can be easily replaced according the needs. Finally, it is worth mentioning that all the accessible external parts are made of insulating material (polyester, plastic, etc.) as protection against electric shock.

Figure 4. External and internal views of the capacitive load boxes. (a) IGBTs, drivers and control circuit. (b) Capacitors and pre-charging circuit.

\subsection{Drive circuit}

Each IGBT is switched from the off state to the on state, and vice versa, by a drive circuit, whose schematic is shown in figure 5. The drive circuit of the IGBT1 has a particularity, not displayed in this schematic, which involves the above mentioned thermal switch placed in series with the push button P2. In order to facilitate the load development, a PCB with the three driver circuits can be downloaded from the UPMIES web page (UPM-IES, 2005).

The core of the drive circuit is an optocoupler that contains a light-emitting diode (LED) optically coupled to an output power stage, which consists of two transistors (T1 and T2). However, this optical isolation facility, which is very often needed between control signals and drive circuits, has not been used here since both, the LED and the 
output stage, are supplied by the same voltage source (Vcc). This voltage source consists of two dry cells of $9 \mathrm{~V}$ connected in series.

The circuit operates this way. When P2 is not pushed (T1 is off and T2 is on), the IGBT gate is shorted to the emitter through the gate resistor, Rg, and the transistor T2, which maintains the IGBT in the off state. On the contrary, when P2 is pushed, the LED emits light that reverses the states of $\mathrm{T} 1$ and $\mathrm{T} 2$ to on and off, respectively. Then, the output optocoupler voltage, Vo, comes close to Vcc, which charges the input capacitance of the IGBT through Rg and switches it to the on state. The recommended gate-emitter voltage, Vge, for commercial IGBTs is $15 \mathrm{~V}$, although a voltage inside of the range from 12 to a maximum of $20 \mathrm{~V}$ can be used. Finally, when P2 is released again, the input capacitance is discharged through $\mathrm{Rg}$ and $\mathrm{T} 2$, returning the IGBT to the off state.

Turn-on and turn-off times depends on the IGBT input capacitance (characteristic of each device) and on the value of Rg. The smaller the latter, the faster the switching times and the lower the power dissipation in the IGBT. However, Rg can not be as small as desired. The minimum value of Rg must ensure that the maximum output current of the optocoupler, Im, is not exceeded (i.e., $\mathrm{Rg} \geq \mathrm{Vo} / \mathrm{Im}$ ).

Figure 5. Drive circuit of each IGBT.

Table 2 shows the electrical characteristics of the drive circuit components. The functions of other components, not mentioned above, are the following. The rectifier diodes, D4 and D5, are used to reduce the supply voltage, Vcc, around $1.2 \mathrm{~V}$. The resistor R4 limits the current through the LED, and C6 is used to absorb the oscillations of the push button P2. The zener diodes, Dz1 and Dz2, limit the gate-emitter voltage to 
a maximum of $\pm 18.6 \mathrm{~V}$ (one diode operating at the breakdown voltage and the other one in the conducting state). Finally, the gate-emitter resistor, Rge, ensures that the IGBT remains in the off state and is not triggered to the on state by the switching of other IGBT, which can happen when the drive circuit of the former is not supplied (as discussed in next section, only one drive circuit is supplied at the same time).

Table 2. Drive circuit components.

\subsection{Control circuit}

The control circuit is shown in figure 6. It simply consists of two bipolar switches operated manually, which only supply the drive circuit $(1,2$ or 3$)$ associated with the required function (array short-circuit, capacitor charge, or capacitor discharge, respectively).

Figure 6. Control circuit.

\subsection{Cost}

Table 3 breaks down the capacitive load cost (retail trade of Madrid) into its different components. The total cost, less than $1000 €$, is within the reach of small-scale organisations involved in PV projects. It is worth mentioning that the load must be used in combination with additional components (a PV sensor, a laptop computer, a data acquisition system, a software tool, etc.), whose cost must be also taken into account.

Regarding the PV sensor, we use a reference module that is calibrated in terms of short-circuit current and open-circuit voltage by a certified PV laboratory (CIEMATMadrid in our case), whose calibration fees are about $500 €$ (Caamaño et al., 1999). 
Concerning the data acquisition system, we use a general-purpose digital oscilloscope that allows to capture $512 \mathrm{I}-\mathrm{V}$ points during the capacitor charging process (the recommended minimum number of captured $\mathrm{I}-\mathrm{V}$ points must be at least 50 (Blaesser, Munro, 1995)). The cost of this oscilloscope amounts to about $2000 €$, although there are less expensive options. For example, PC-based digital oscilloscopes are commercially available from $500 €$. Finally, the software tool required to extrapolate the I-V characteristics to STC can be implemented with a conventional spreadsheet without additional cost.

Table 3. Components cost of the load.

\section{OUTDOOR CHARACTERIZATION PROCEDURE}

The characterization procedure of a PV array consists of two stages. The first one involves the measurement of one or more I-V characteristics together with the simultaneous readings of in-plane irradiance and operating temperature of solar cells. Besides, as STC conditions seldom occur outdoors (especially in which concerns to the $25{ }^{\circ} \mathrm{C}$ cell temperature), the second stage involves the determination of the array rated power, which requires to extrapolate the measured I-V characteristics to STC.

The measurement of I-V characteristics has been already described above and does not deserve much more attention, with the exception of two considerations. On one side, the array must be disconnected from any load (battery, inverter, etc.) about 5 minutes before to initiate the measurement, which is usually enough to reach a stable thermal condition for typical glass-tedlar modules. On the other side, the measurement must be done under acceptable environmental conditions, which are defined by (Caamaño et al., 2002): in-plane irradiance higher than $600 \mathrm{~W} / \mathrm{m}^{2}$, diffuse fraction of 
irradiance less than $20 \%$ (clear day), incidence angle of sun beams less than $40^{\circ}$, AM less than 1.5 and wind speed less than $8 \mathrm{~m} / \mathrm{s}$.

Regarding the measurement of operating conditions, we use a reference PV module (with the same technology and similar size as the modules of the array to be measured) as irradiance and cell temperature sensor through indirect measurements of its short-circuit current and open-circuit voltage, respectively (Caamaño et al., 2002). This reference PV module must be placed coplanar with the array (figure 7) in order to correct spectral, irradiance and thermal effects.

Figure 7. Reference module used as irradiance and cell temperature sensor.

Finally, concerning the methods of extrapolation of the measured I-V characteristics to STC, they have been widely treated in the literature (see, as illustrative examples: Blaesser, Munro, 1995; IEC, 1995) and a detailed discussion about them is beyond the scope of this paper. Nevertheless, it is worth mentioning that any of these methods ensure an overall accuracy of the extrapolated power at STC within $\pm 5 \%$ for irradiances higher than $600 \mathrm{~W} / \mathrm{m}^{2}$. If a better accuracy is required, for example, in the frame of contractual acceptance procedures, it is necessary to perform the measurements with irradiances close to $1000 \mathrm{~W} / \mathrm{m}^{2}$. For example, the figure 8 shows the measured I-V characteristic of a PV array using the capacitive load described in this paper and its subsequent extrapolation to STC following the recommendations issued by the JRCIspra (Blaesser, Munro, 1995).

Figure 8. Measured I-V characteristics of a PV array $\left(759.4 \mathrm{~W} / \mathrm{m}^{2}\right.$ irradiance and 54.3

${ }^{\circ} \mathrm{C}$ cell temperature) and extrapolation to STC. 


\section{CONCLUSIONS}

The electronic design of a portable capacitive load based on IGBTs has been presented in this paper with the aim of encouraging the use and development of similar equipment beyond the realm of research laboratories or universities. The load allows to measure the I-V curve of PV arrays with short-circuit currents up to 80 A and opencircuit voltages up to $800 \mathrm{~V}$. Besides, it is easy to reproduce and low-cost, which is within the reach of small-scale organisations involved in PV electrification projects.

\section{REFERENCES}

Barbisio, E., 1996. Improved three-quadrants voltage-to-current curve tracer by a LC load. $25^{\text {th }}$ IEEE Photovoltaic Specialists Conference, pp. 1283-1286.

Blaesser, G., Munro, D., 1995. Guidelines for the Assessment of Photovoltaic Photovoltaic Plants. Document C. Initial and Periodic Tests on PV plants. Joint Research Centre Ispra. European Commission.

Caamaño, E., Lorenzo, E., Zilles, R., 1999. Quality control of wide collections of PV modules: lessons learned from the IES experience. Progress in Photovoltaics: Research and Applications. Vol. 7, Issue 2, pp. 137-149.

Caamaño, E., Lorenzo, E., Lastres, C., 2002. Crystalline silicon photovoltaic modules: characterization in the field of rural electrification. Progress in Photovoltaics: Research and Applications. Vol. 10, Issue 7, pp. 481-493.

IEC, 1995. International Standard 61829. Crystalline silicon photovoltaic (PV) array On-site measurement of I-V characteristics. 
Lorenzo, E., Zilles, R., 1994. PV modules and arrays test at 1 MW Toledo PV plant. $12^{\text {th }}$ European Photovoltaic Solar Energy Conference, pp. 807-809.

Muñoz, J., Narvarte, L., Lorenzo, E., 2003. Replacement of diesel generators by small PV plants. Proceedings of the $2^{\text {nd }}$ European PV-Hybrid and Mini-Grid Conference, pp. 157-162.

Narvarte, L., Poza, F., Lorenzo, E., 2004. Technical Quality in a PV Pumping Program in the Maghreb. $19^{\text {th }}$ European Photovoltaic Solar Energy Conference, pp. 2234-2237.

Neuenstein, H., Albers, K., 2004. On-site power checks. Photon International, May, pp. 70-74.

UPM-IES, 2005. Web page: www.ies.upm.es. English site map: R\&D Programs $\backslash$ Systems $\backslash$ Specific activities $\backslash$ Biblioteca $\backslash$ Buscar. 


\section{TABLES}

\begin{tabular}{|lll|}
\hline Component & Description & Electrical characteristics \\
\hline C1 to C4 & Aluminium electrolytic capacitors & $450 \mathrm{~V} / 4700 \mu \mathrm{F}$ \\
D1 & Diode rectifier & $200 \mathrm{~A} / 1200 \mathrm{~V}$ \\
D2 & Diode rectifier & $100 \mathrm{~A} / 1200 \mathrm{~V}$ \\
D3 & Diode rectifier & $40 \mathrm{~A} / 1200 \mathrm{~V}$ \\
F1 & Fuse & $2 \mathrm{~A}$ \\
F2 & Fuse & $1 \mathrm{~A}$ \\
IGBT 1, 2, 3 & IGBT module MG100Q2YS50 & $100 \mathrm{~A} / 1200 \mathrm{~V}$ \\
R1 & Resistor & $100 \mathrm{k} \Omega$ / 14 W / 750 V \\
R2 & Potentiometer & $10 \mathrm{k} \Omega$ / 0,5 W / 300 V \\
R3 & Resistor & $47 \mathrm{k} \Omega / 9 \mathrm{~W} / 500 \mathrm{~V}$ \\
RD & Power resistor & $470 \Omega / 150 \mathrm{~W} / 2500 \mathrm{~V}$ \\
RP & Resistor & $10 \Omega / 25 \mathrm{~W} / 160 \mathrm{~V}$ \\
RS & Precision resistor & $2.5 \mathrm{~m} \Omega / 60 \mathrm{~A}$ \\
VB & Dry cells & $9 \mathrm{~V}$ \\
\hline
\end{tabular}

Table 1. Power circuit components.

\begin{tabular}{|lll|}
\hline Component & Description & Electrical characteristics \\
\hline C5 & Electrolytic capacitor & $470 \mu \mathrm{F} / 25 \mathrm{~V}$ \\
C6 & Polyester capacitor & $0.15 \mu \mathrm{F} / 25 \mathrm{~V}$ \\
Dz1, Dz2 & Zener diode & $18 \mathrm{~V} / 1 \mathrm{~W}$ \\
IGBT Driver & Optocoupler HCPL-3120 & $2 \mathrm{~A}$ output current \\
R4 & Resistor & $1 \mathrm{k} \Omega / 0.5 \mathrm{~W}$ \\
Rg & Gate resistor & $5.6 \Omega / 0.5 \mathrm{~W}$ \\
Rge & Resistor & $47 \mathrm{k} \Omega / 0.5 \mathrm{~W}$ \\
Vcc & Dry cells & $18 \mathrm{~V}$ \\
\hline
\end{tabular}

Table 2. Drive circuit components.

\begin{tabular}{|lc|}
\hline Component & Cost [€] \\
\hline 4 Aluminium electrolytic capacitors & 250 \\
2 IGBT modules & 200 \\
2 Polyester boxes & 170 \\
3 Voltage panel meters & 100 \\
3 Power diodes & 40 \\
2 Calibrated shunts & 40 \\
1 Aluminium heat sink & 20 \\
Drive circuit (PCB and components) & 20 \\
Other accessories (wiring, connectors, etc.) & 60 \\
Total & 900 \\
\hline
\end{tabular}

Table 3. Components cost of the load. 


\section{LIST OF FIGURES}

Figure 1. (a) Ideal capacitive load composed of a switch and a capacitor. (b) Current and voltage waveforms after closing the switch in $\mathrm{t}=0$.

Figure 2. Ideal (continuous line) and real (dotted line) I-V characteristics of a PV array.

Figure 3. Power circuit.

Figure 4. External and internal views of the capacitive load boxes.(a) IGBTs, drivers and control circuit. (b) Capacitors and pre-charging circuit.

Figure 5. Drive circuit of each IGBT.

Figure 6. Control circuit.

Figure 7. Reference module used as irradiance and cell temperature sensor.

Figure 8. Measured I-V characteristics of a PV array $\left(759.4 \mathrm{~W} / \mathrm{m}^{2}\right.$ irradiance and 54.3 ${ }^{\circ} \mathrm{C}$ cell temperature) and extrapolation to STC. 


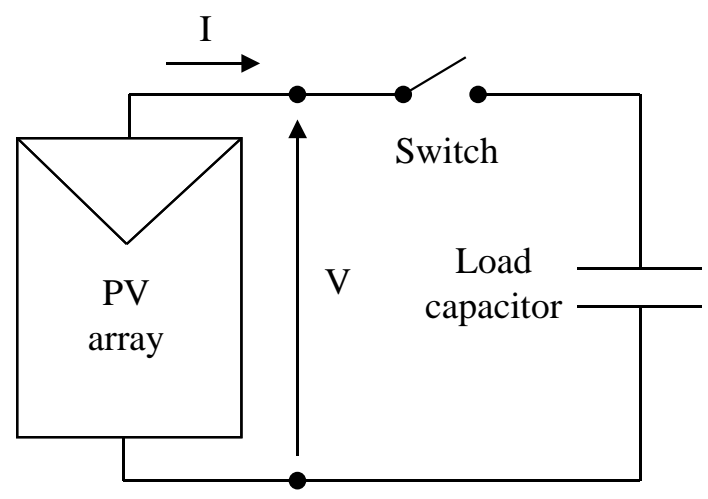

(a)

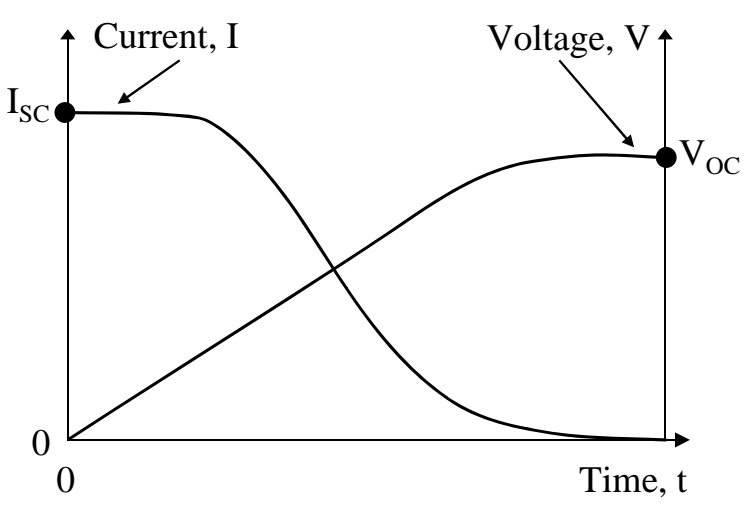

(b)

Figure 1. (a) Ideal capacitive load composed of a switch and a capacitor.

(b) Current and voltage waveforms after closing the switch in $\mathrm{t}=0$. 


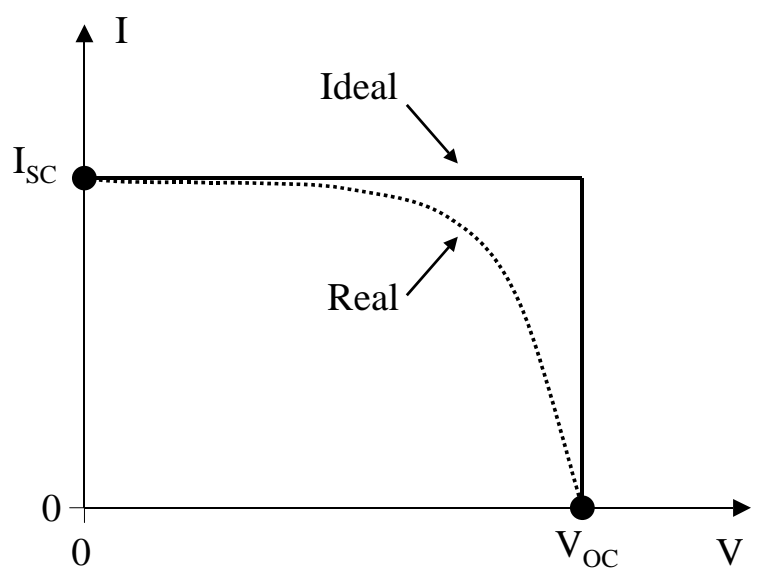

Figure 2. Ideal (continuous line) and real (dotted line) I-V characteristics of a PV array. 


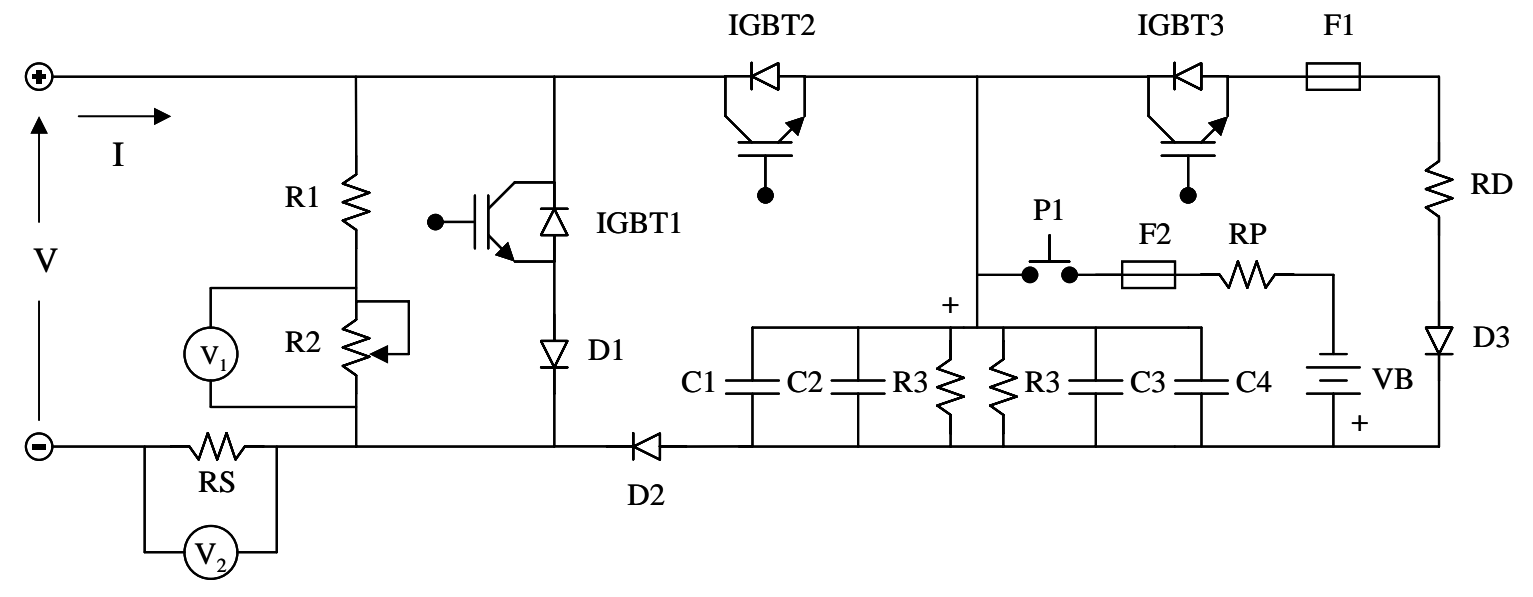

Figure 3. Power circuit. 

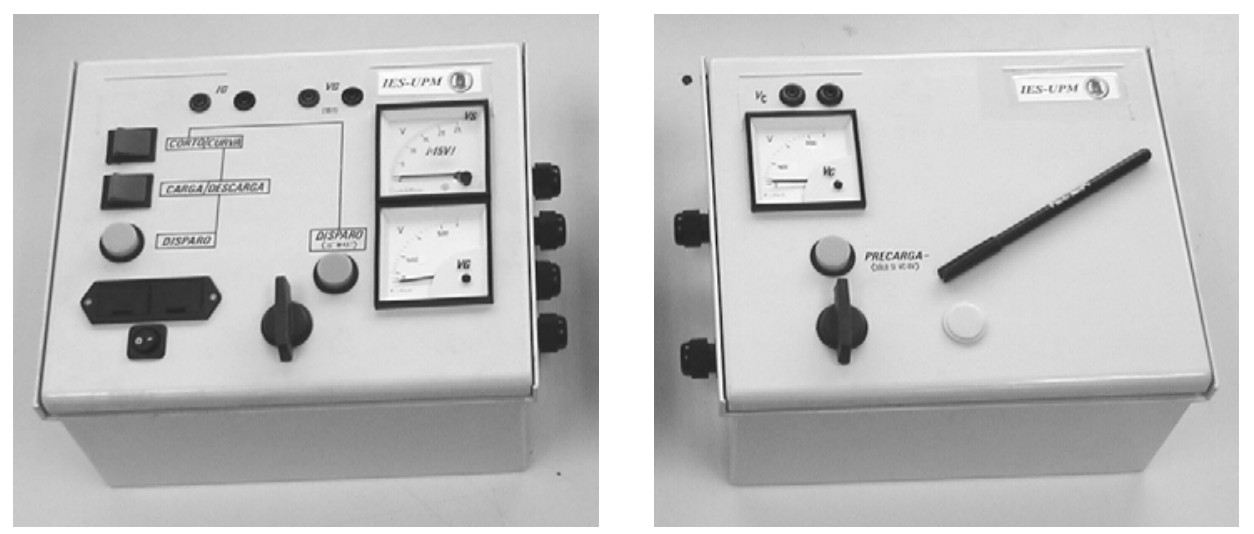

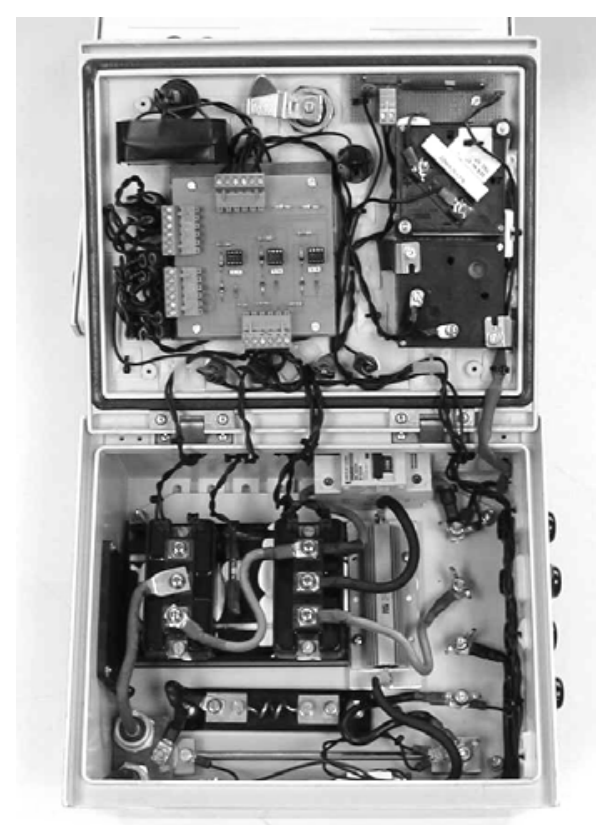

(a)

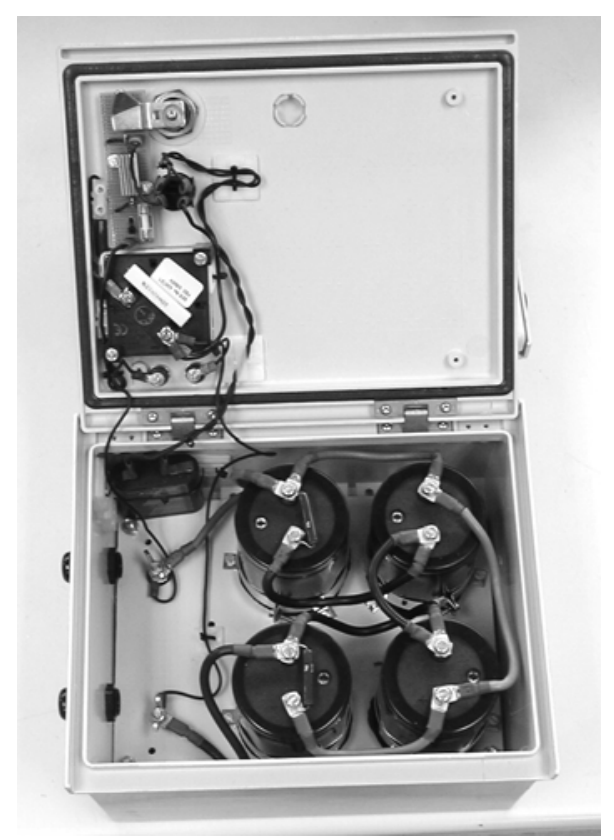

(b)

Figure 4. External and internal views of the capacitive load boxes. (a)

IGBTs, drivers and control circuit. (b) Capacitors and pre-charging circuit. 


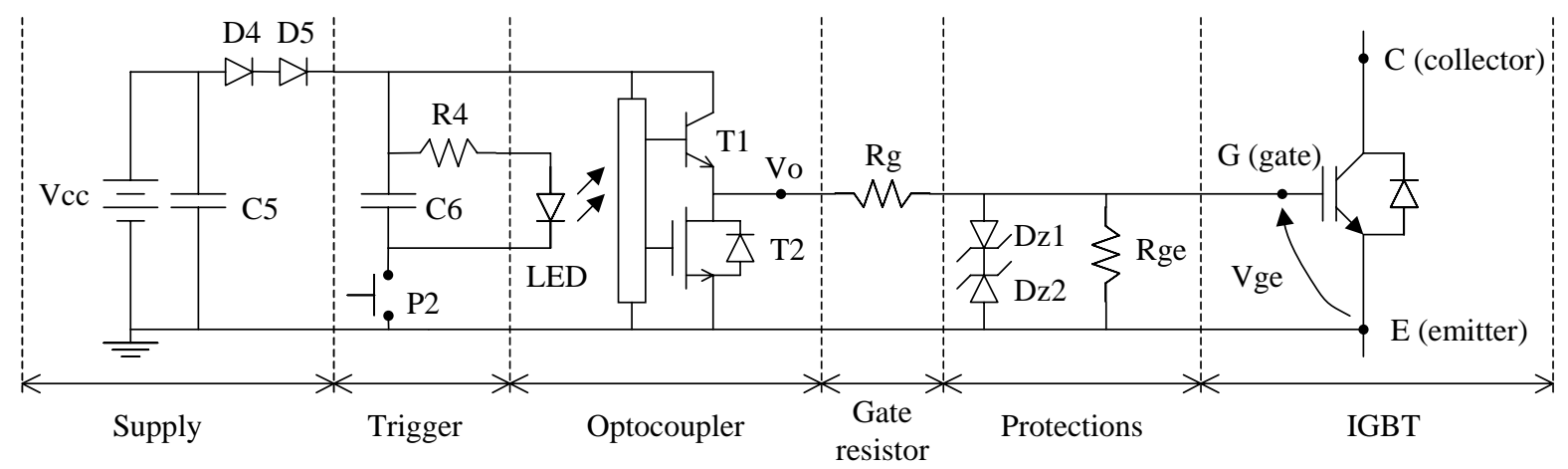

Figure 5. Drive circuit of each IGBT. 


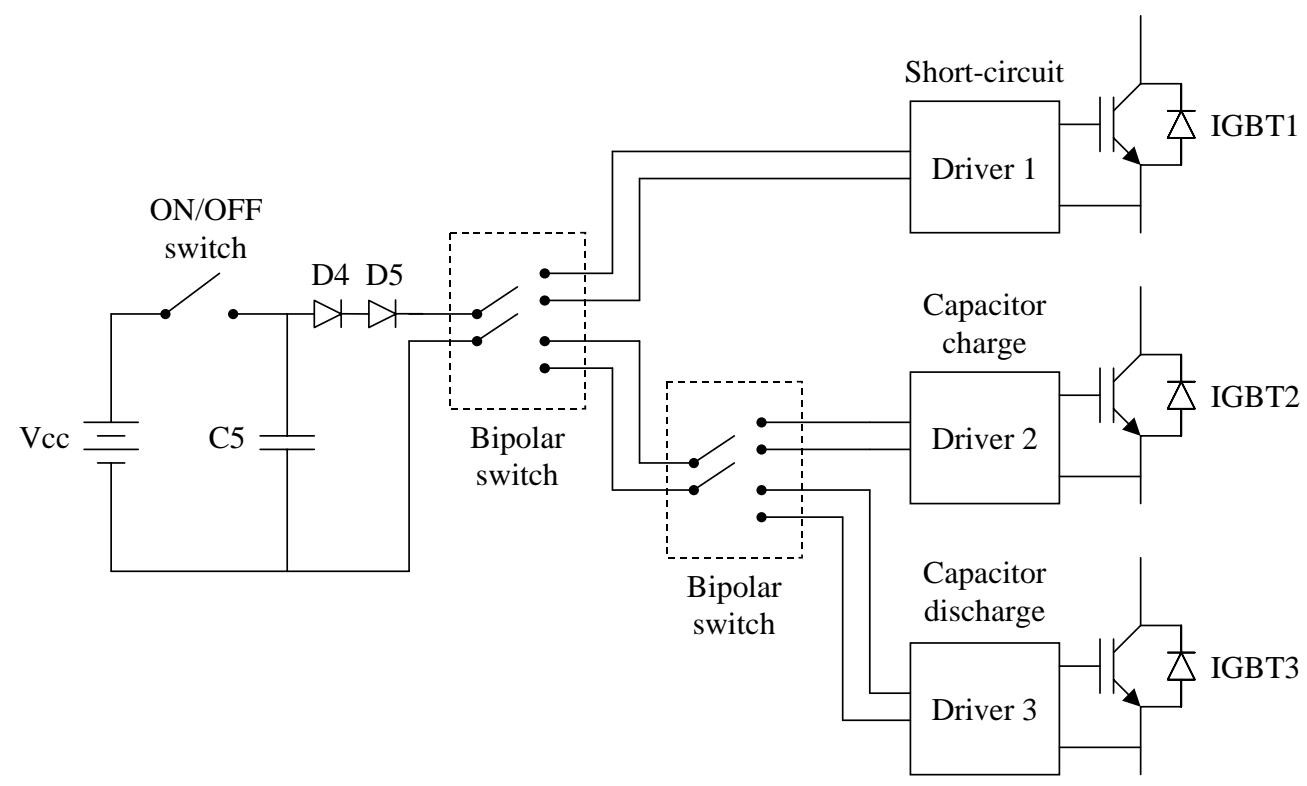

Figure 6. Control circuit. 


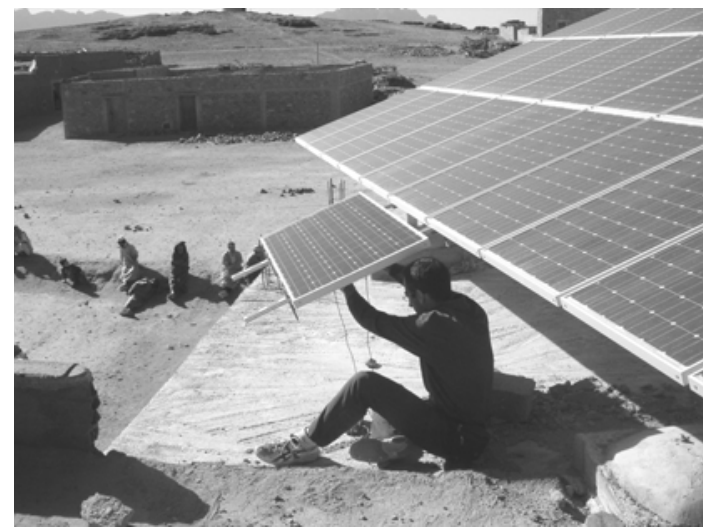

Figure 7. Reference module used as irradiance and cell temperature sensor. 


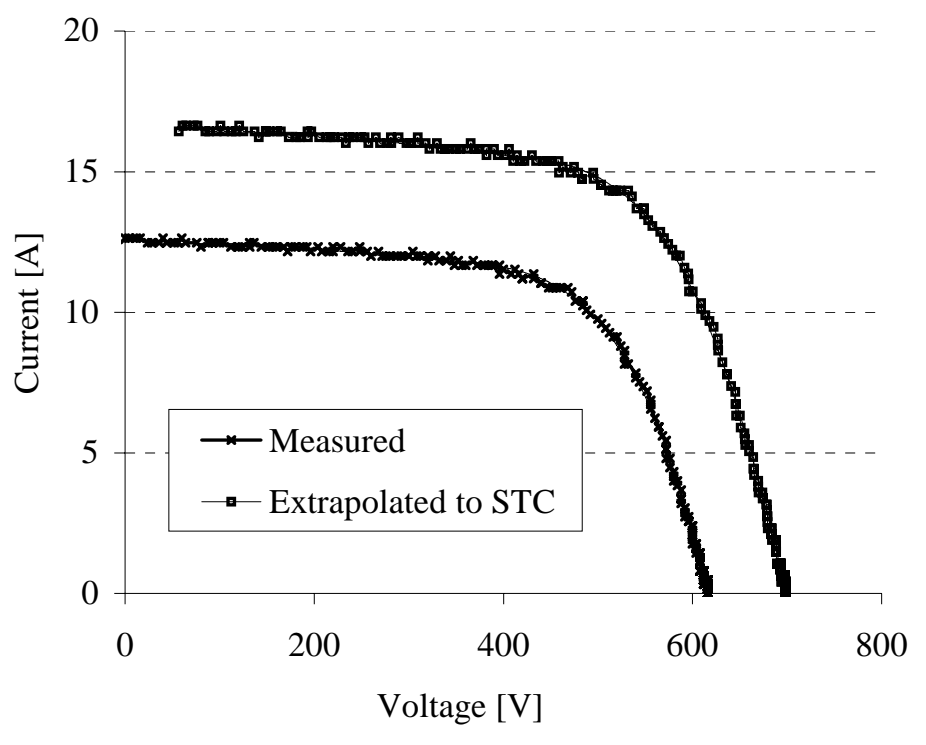

Figura 8. Measured I-V characteristics of a PV array $\left(759.4 \mathrm{~W} / \mathrm{m}^{2}\right.$ irradiance and $54.3^{\circ} \mathrm{C}$ cell temperature) and extrapolation to STC. 